GRASAS Y ACEITES 65 (3)

July-September 2014, e032

ISSN-L: 0017-3495

doi: http://dx.doi.org/10.3989/gya.0111141

\title{
Phenolic content of Sicilian virgin olive oils and their effect on MG-63 human osteoblastic cell proliferation
}

\author{
O. García-Martínez ${ }^{\mathrm{a}}$, G. Mazzaglia ${ }^{\mathrm{a}, \mathrm{b}}$, A. Sánchez-Ortiz ${ }^{\mathrm{c}}$, F.M. Ocaña-Peinado ${ }^{\mathrm{d}}$ and A. Rivas ${ }^{\mathrm{e}, \bigotimes}$ \\ ${ }^{a}$ Faculty of Health Sciences, University of Granada, Avda de Madrid s/n, 18071, Granada, Spain \\ ${ }^{\mathrm{b}}$ Private practice, via Garibaldi 2, 95047 Paternò, Sicily, Italy \\ ${ }^{\mathrm{c} A g r i c u l t u r a l ~ R e s e a r c h ~ T r a i n i n g ~ C e n t r e, ~ M i n i s t r y ~ o f ~ A g r i c u l t u r e ~ a n d ~ F i s h e r i e s, ~ C t r a . ~ B a i l e n-M o t r i l, ~}$ \\ 23620, Km. 18,5, Mengibar, Jaén, Spain \\ ${ }^{\mathrm{d} D e p a r t m e n t ~ o f ~ S t a t i s t i c s ~ a n d ~ O p e r a t i o n s ~ R e s e a r c h, ~ F a c u l t y ~ o f ~ P h a r m a c y, ~ U n i v e r s i t y ~ o f ~}$ \\ Granada, Campus de Cartuja s/n, 18071, Granada, Spain \\ ${ }^{e}$ Faculty of Pharmacy, University of Granada, Campus de Cartuja s/n, 18071, Granada, Spain \\ Corresponding author: amrivas@ugr.es
}

Submitted: 15 January 2014; Accepted: 20 March 2014

SUMMARY: The aim of this study was, first, to investigate the influence of olive variety and elevation of orchards on the phenolic compound content of Sicilian virgin olive oils (VOOs) and, second, to investigate the effects of VOO phenolic extracts on osteoblast cell growth using the human MG-63 osteosarcoma cell line. Olive oil phenolic content and its effect on human osteosarcoma cell proliferation varied according to the type of cultivar and the grove altitude. This variation was also observed within the same type of cultivar. This observation demonstrates that the cultivar and the grove location can significantly affect the chemical composition and bioactivity of virgin olive oil. Although this study supports the hypothesis that virgin olive oil phenolic fractions exert a beneficial effect on bone health, further studies assessing the in vivo accessibility of virgin olive oil phenolic compounds to osteoblast cells should be carried out.

KEYWORDS: Osteoblastic cells; Phenolic compounds; Proliferation; Sicily; Virgin olive oil

RESUMEN: Contenido fenólico de aceites de oliva vírgenes de Sicilia y su efecto sobre la proliferación celular de osteoblastos humanos MG-63. El objetivo del presente trabajo es investigar la influencia de la variedad y la altitud del cultivo en el contenido fenólico de aceites de oliva virgen Sicilianos. Asimismo, se ha investigado el efecto de los extractos fenólicos de los aceites en el crecimiento de osteoblastos usando la línea celular de osteosarcoma humano MG-63. El contenido fenólico y el efecto de los extractos analizados en la proliferación de la línea celular osteoblástica muestra una variabilidad consistente de acuerdo con el tipo y la altitud del cultivo. Estos datos demuestran que estas características pueden afectar significativamente la composición química y los efectos en salud del aceite de oliva virgen. Los resultados de este trabajo soportan la hipótesis de que las fracciones fenólicas de los aceites de oliva vírgenes ejercen un efecto beneficioso en la salud ósea. Asimismo, se deben realizar más estudios que establezcan la accesibilidad in vivo de los compuestos fenólicos del aceite de oliva virgen a las células osteoblásticas.

PALABRAS CLAVE: Aceite de oliva virgen; Células osteoblásticas; Compuestos fenólicos; Proliferación; Sicilia

Citation/Cómo citar este artículo: García-Martínez O, Mazzaglia G, Sánchez-Ortiz A, Ocaña-Peinado FM, Rivas A. Phenolic content of Sicilian virgin olive oils and their effect on MG-63 human osteoblastic cell proliferation. Grasas Aceites 65 (3): e032. doi: http://dx.doi.org/10.3989/gya.0111141.

Copyright: (c) 2014 CSIC. This is an open-access article distributed under the terms of the Creative Commons Attribution-Non Commercial (by-nc) Spain 3.0 Licence. 


\section{INTRODUCTION}

The olive tree is one of the most important crops in Mediterranean countries, especially in Spain, Greece, Tunisia and Italy (Baccouri et al., 2007). Sicily has a long history of olive cultivation and is an important olive producing area (Poiana and Romeo, 2006). The large size of the island and its particularly fertile soil, which in Eastern regions is volcanic, allows for olive cultivation in many microclimates. Olives grown in the volcanic soil on the slopes of Mount Etna absorb minerals from the soil that subsequently produce a characteristic oil variety.

Considerable research has focused on the biologically active phenolic compounds naturally present in virgin olive oils (VOOs) to aid in the understanding of the beneficial effects of the traditional Mediterranean diet. The most important phenolic compounds in VOO are phenolic acids and alcohols, secoiridoids, lignans, and flavonoids (Bendini et al., 2007). The phenol content may be affected by many factors, such as the olive variety, soil, altitude, region, time of harvest and extraction process (Jiménez et al., 2013). It has been demonstrated that the location in which olives are grown has a significant effect on the composition of olive oils of the same cultivar (Ouni et al., 2012). The health benefits of virgin olive oils produced in the same geographical area may vary according to their phenolic compound contents.

Despite the myriad of potential health benefits of olive oil phenolic compounds, little information is available on the potential preventive effects of olive oil phenolic compounds on osteoporosis (Hagiwara et al., 2011; Puel et al., 2007, 2008). In Europe, clear differences are observed in the severity of osteoporosis, the lowest incidence has been reported in the Mediterranean area (Puel et al., 2007). This occurrence has been attributed to a diet rich in olive oil (Fernández-Real et al., 2012, Rivas et al., 2013). It has been shown that the consumption of olives, olive oil, and oleuropein as well as hydroxytyrosol, the main phenolic compounds found in olive leaves and fruit, respectively, can prevent the loss of bone mass in animals (Puel et al., 2007). Moreover, in vivo and in vitro studies have shown that luteolin, a flavonoid present in VOO, reduces the loss of bone mass in patients with postmenopausal osteoporosis by reducing osteoclast differentiation and function (Lee et al., 2009, Kim et al., 2011). However, the luteolin concentration used in these experiments was higher than those found in virgin olive oil samples.

It should be noted that the in vivo biological properties of olive oil phenolic compounds depend on gastrointestinal stability and the extent of absorption and metabolism of the compounds (Mateos et al., 2011). The metabolic fate of phenolic compounds after ingestion has been a key area of research and investigation concerning the in vivo mechanisms by which such compounds are effective (Suarez et al., 2011). In the case of VOO, studies have focused on specific compounds, such as hydroxytyrosol and tyrosol. Visioli et al. (2002) identified these compounds in urine, both in conjugated and free forms. Alternatively, the study by Miró-Casas et al. (2003) reported the presence of the conjugated forms of hydroxytyrosol in plasma. Moreover, Corona and coworkers (2006) conducted a detailed investigation on the absorption, metabolism and microfloradependent transformation of the virgin olive oil phenolic compounds hydroxytyrosol, tyrosol and their conjugated forms, such as oleuropein. The conjugated forms underwent rapid hydrolysis under gastric conditions, resulting in significant increases in the amount of free hydroxytyrosol and tyrosol entering the small intestine. In addition, Mateos and coworkers (2011) showed that both hydroxytyrosol acetate and hydroxytyrosol were transferred across human Caco-2/TC7 cell monolayers.

Currently, the most widely used approach in the examination of the potential relationship between VOO phenolic compounds and bone health is based on specific phenolic compounds, such as oleuropein (Santiago-Mora et al., 2011). However, this analysis lacks information regarding the complex interactions among these compounds. It has been established that individual phenolic compounds and phenolic fractions that mainly contained a sole phenolic compound were not equivalent in their abilities to inhibit human breast cancer cell growth (LozanoSánchez et al., 2010). Therefore, it is necessary to consider that a combinatorial effect is possible between phenolic compounds and other substances present in phenolic extracts. In this regard, in vitro studies should always consider the effect of olive oil active fractions to investigate and promote the development of appropriate recommendations for overall dietary habits.

Accordingly, the first aim of this study was to investigate the influence of the olive variety and the elevation of the orchards on the phenolic compound content of Sicilian virgin olive oils. In addition, because the biological activity of VOO phenols appears to have combinatorial effects, the second aim was to examine the effects of VOO phenolic extracts on osteoblast cell growth using the human MG-63 osteosarcoma cell line.

\section{MATERIAL AND METHODS}

\subsection{Chemicals}

Standards of apigenin, luteolin, hydroxytyrosol, tyrosol, vanillin and $p$-coumaric, ferulic, and vanillic acids were purchased from Sigma-Aldrich (St. Louis, MO) and (+)-pinoresinol was purchased from ArboNova (Turku, Finland). Stock solutions of phenolic 
compounds were prepared in methanol and stored at $-20^{\circ} \mathrm{C}$. All of the solvents used were of analytical or HPLC grade (Sigma-Aldrich). The water was of Milli-Q quality (Millipore Corp, Bedford, MA, USA).

\subsection{Oil Samples}

Sicilian olive samples from eight different cultivars (Biancolilla, Passulunara, Tonda iblea, Nocellara del belice, Nocellara del belice Organic and Nocellara etnea from three different altitudes) were provided by Sicilian oil producers. Olives were hand-picked at the same stage of maturity and the same laboratory mill was used to prepare olive oil samples. Virgin olive oil samples were obtained using an Abencor analyzer (Abengoa S.A., Seville, Spain). This system reproduces the industrial process at a laboratory scale and consists of three basic elements: hammer mill, thermo-beater, and pulp centrifuge (Martínez et al., 1975). The milling of olive fruits was performed using a stainless-steel hammer mill operating at $3000 \mathrm{rpm}$ equipped with a $5 \mathrm{~mm}$ sieve. The resulting olive paste was immediately kneaded in a mixer at $50 \mathrm{rpm}$ for $30 \mathrm{~min}$ at $30{ }^{\circ} \mathrm{C}$. Centrifugation of the kneaded olive paste was performed in a basket centrifuge at $3500 \mathrm{rpm}$ for $1 \mathrm{~min}$. After centrifugation, the oil obtained was decanted and stored in amber glass bottles at $4{ }^{\circ} \mathrm{C}$ in the dark and without headspace until analysis.

\subsection{Phenolic compounds}

To isolate the phenolic fraction of olive oils, the method proposed by the International Olive Oil Council (IOOC, 2009) was used. Briefly, the analytical methodology consists of olive oil extraction with methanol/water (80/20), an ultrasonic bath for $15 \mathrm{~min}$ at ambient temperature and centrifugation at $5000 \mathrm{rpm}$ for $25 \mathrm{~min}$. After that, an aliquot of the supernatant phase is filtered through a $5 \mathrm{~mL}$ plastic syringe using a Millex ${ }^{\mathrm{N}}-\mathrm{HV}$ PVDF $0.45 \mu \mathrm{m}$ filter (Millipore Corp, Billerica, MA, USA). The extractions were repeated three times, and phenolic extracts were stored at $-20{ }^{\circ} \mathrm{C}$ until further analysis. The total phenolic content was measured by HPLC using a UV-Vis detector in accordance with IOOC's methodology (IOOC, 2009). Syringic acid was used as the internal standard. HPLC analyses were performed with a Varian ProStar HPLC unit (Walnut Creek, CA, USA) equipped with a Varian 230 UV-Vis detector. The total phenolic contentexpressed in $\mathrm{mg} \cdot \mathrm{kg}^{-1}$ of tyrosol-was calculated by measuring the sum of the areas of the related chromatographic peaks, according to the method proposed by the IOOC. Secoiridoid compounds were quantified at $280 \mathrm{~nm}$ using the response factors determined by Mateos et al. (2011).

When standards were available (apigenin, luteolin, hydroxytyrosol, tyrosol, vanillin, $(+)$-pinoresinol and $p$-coumaric, ferulic, and vanillic acids), ultra performance liquid chromatography coupled to time-of-flight mass spectrometry analysis (UPLCTOF-MS) were performed to detect and quantify individual phenolic compounds in phenolic extracts. The UPLC system consisted of an AcQuity TM UPLC equipped with a binary pump system (Waters, Milford, MA, USA) and an AcQuity UPLC ${ }^{\mathrm{TM}}$ BEH C18 column $(1.7 \mu \mathrm{m}, 100 \mathrm{~mm} \times 2.1 \mathrm{~mm}$ i.d.) from Waters. The UPLC-TOF-MS methodology was described elsewhere (Jiménez et al., 2013; Rivas et al., 2013). The identification of phenolic compounds was carried out by comparing both the retention times and MS spectra from the olive oil samples and standards when available.

\subsection{Cell Culture}

The human osteosarcoma cell line MG-63 was purchased from American Type Cultures Collection (ATCC, Manassas, VA) and maintained in Dulbecco's Modified Eagle Medium (DMEM; Invitrogen Gibco Cell Culture Products, Carlsbad, CA) with $100 \mathrm{IU} / \mathrm{ml}$ penicillin (Lab Roger SA, Barcelona, Spain), $50 \mu \mathrm{g} \cdot \mathrm{mL}^{-1}$ gentamicin (Braum Medical SA, Jaen, Spain), $2.5 \mu \mathrm{g} \cdot \mathrm{mL}^{-1}$ amphotericin B (Sigma, St Louis, MO, USA), 1\% glutamine (Sigma, St Louis, MO, USA), and 2\% HEPES (Sigma, St Louis, MO, USA) and was supplemented with $10 \%$ foetal bovine serum (FBS) (Gibco, Paisley, UK). Cultures were kept at $37{ }^{\circ} \mathrm{C}$ in a humidified atmosphere of $95 \%$ air and $5 \% \mathrm{CO}_{2}$. Cells were detached from the culture flask with a solution of $0.05 \%$ Trypsin (Sigma, St Louis, MO, USA) and $0.02 \%$ ethylenediaminetetraacetic acid (EDTA) (Sigma, St Louis, MO, USA) and were then washed and suspended in a complete culture medium with $10 \%$ FBS. Prior to the beginning of each experiment, all of the cells were grown in oestrogen-free media (DMEM without red phenol) for at least 24 hours.

\subsection{Cell Proliferation Assay}

Cell proliferation was determined using the MTT method (Sigma-Aldrich Chemie). This is a colorimetric method that measures the chemical reduction of MTT (3-(4,5-dimethylthiazol-2-yl)-2,5-diphenyltetrazolium bromide) into formazan, which is directly proportional to the number of viable cells in the tested sample. Osteoblasts were seeded at $1 \times 10^{4}$ cells $\cdot \mathrm{mL}^{-1}$ per well into a 96 -well plate (Falcon Becton Dickinson Labware, New Jersey) in an oestrogen-free culture medium without FBS and cultured at $37^{\circ} \mathrm{C}$ in a humidified atmosphere of $95 \%$ air and $5 \% \mathrm{CO}_{2}$ for 24 hours. Then, the media was replaced with DMEM containing different concentrations of prepared phenolic extracts dissolved in a fresh culture medium at concentrations of $0.001,0.0001$ and $0.00001 \%$. All of the experiments included cells incubated under 
the same conditions without treatment extracts and cells incubated with $0.001 \%$ methanol as an internal control. The highest solvent concentration in culture media $(0.001 \% \mathrm{v} / \mathrm{v}$ methanol) had no significant effects on cell proliferation. Upon completion of the treatment, the media was replaced with DMEM, without phenol-red, containing $0.5 \mathrm{mg} \cdot \mathrm{mL}^{-1}$.

MTT (Sigma, St Louis, MO, USA) and was incubated for 4 hours. Cellular reduction of the tetrazolium ring of MTT resulted in the formation of formazan crystals in the form of dark-purple, waterinsoluble deposits. After incubation, the media was aspired and DMSO was added to dissolve the formazan crystals. Absorbance was measured at $570 \mathrm{~nm}$ with a spectrophotometer (Sunrise TM, Tecan, Männedorf, Switzerland). Cell proliferation percentages $(\%>$ control $)$ were calculated compared to cell cultures treated with methanol alone (controls).

\subsection{Statistical Analysis}

A statistical analysis was performed using SPSS (v. 20.0, Statistical Package for the Social Sciences, Chicago, IL). Numerical data on cell proliferation are expressed as the mean of three independent experiments. Statistically significant differences in the effects on proliferation between the extracts and the control were analyzed by the Student's t-test. The results for phenolic compounds are the average of at least three repetitions. A two-way analysis of variance (ANOVA) was performed to examine the proliferation by considering the concentration, the olive oil variety and the interaction between these two factors. A one-way ANOVA was used to examine phenolic compound concentrations by considering the olive oil variety. The homogeneity between the olive oil variety samples was tested using the Levene's test. Differences between the means were evaluated using the Games-Howell and Bonferroni tests. The significance level in all of the statistical analyses was set at 0.05 . The level of significance of differences between the phenolic compound mean values was determined at $5 \%$ by a one-way ANOVA using Tukey's test. Principal components analysis (PCA) was applied to the chemical and proliferation data. PCAs were carried out for all raw data processed with a cross-validation method. The data were auto-scaled before analysis.

\section{RESULTS AND DISCUSSION}

\subsection{Identification and quantification of phenolic compounds in VOO}

Phenolic compounds are an essential component of VOO quality. The most important phenolic compounds that have been identified in VOO are divided into different groups, such as phenolic acids, phenol alcohols, secoiridoids, lignans, and flavones (Bendini et al., 2007). In this study, the concentrations of phenolic compounds were determined in olive oil samples that were collected from different Sicilian olive tree cultivars. Table 1 shows the mean values for the total and individual phenolic compounds detected in oils.

The total phenolic content of Sicilian oils was measured by HPLC using a UV-Vis detector in accordance with IOOC's methodology (2009). The differences found in the phenol content among the diverse VOO samples are as expected, as the phenolic content of virgin olive oil is influenced by the type of cultivar, production method and altitude. The oil sample obtained from the Nocellara etnea variety, which is produced at an altitude of $100 \mathrm{~m}$, was the sample with the highest amount of phenolic compounds, while the samples obtained from the Tonda iblea variety contained the lowest. The total phenolic compound contents in the varieties examined in this study were higher than those measured in other studies using spectrophotometry methods (Baccouri et al., 2007; Dugo et al., 2004; Patumi et al., 2003) but were similar to those measured using chromatographic analysis (Saitta et al., 2002).

Significant quantitative differences in the total phenol contents were observed in Nocellara etnea olive oils produced at different altitudes. The highest concentration of phenols was observed in olive oils obtained from plants cultivated at $100 \mathrm{~m}$, and Nocellara etnea olives grown at a higher altitude $(900 \mathrm{~m})$ showed the lowest levels of phenolic compounds. This result is contradictory to several reports in which the total phenol content is positively correlated with altitude (Mousa et al., 1996; Ouni et al., 2012).

The phenol alcohols found in the olive oils studied were hydroxytyrosol and tyrosol. The concentration of hydroxytyrosol $\left(4.26-9.93 \mathrm{mg} \cdot \mathrm{kg}^{-1}\right)$ was generally higher than that of tyrosol $\left(2.12-4.53 \mathrm{mg} \cdot \mathrm{kg}^{-1}\right)$ and was similar to that reported by other authors (Baccouri et al., 2007). The highest concentrations of these compounds were observed in Nocellara del belice olive oils. In this variety, the mean values of hydroxytyrosol were higher in olive oils obtained from conventionally cultivated olive trees than in those obtained from organic cultivation. Nocellara etnea olive oils from olives grown at a higher altitude have greater tyrosol and hydroxytyrosol concentrations than Nocellara etnea oils obtained from olives grown at an altitude of $0 \mathrm{~m}$.

The most abundant phenolic compounds found in the VOOs under study were secoiridoids. The concentrations of these compounds ranged from 0.3 to $54.31 \mathrm{mg} \cdot \mathrm{kg}^{-1}$. In general, these results agree with those found by other authors in the Nocellara del Belice and Biancolilla olive oil varieties (Baccouri et al., 2007). However, the secoiridoid concentrations in Tonda iblea olive oil were lower than those previously reported (Napolitano et al., 2008). In general, the secoiridoid content of Nocellara del belice olive oils obtained from conventional cultivation is 
Phenolic content of Sicilian virgin olive oils and their effect on MG-63 human osteoblastic cell proliferation $• 5$

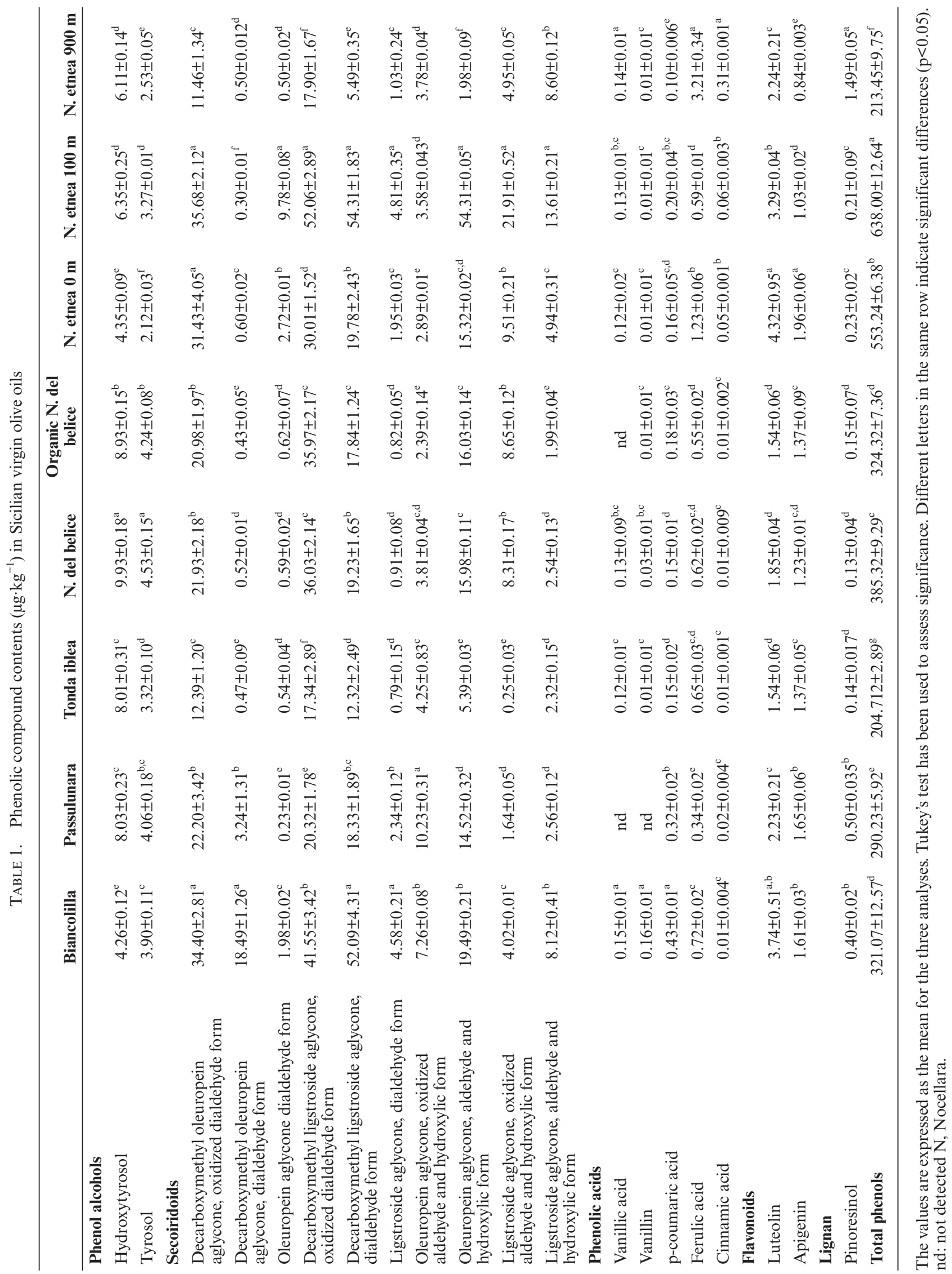

Grasas Aceites 65 (3), July-September 2014, e032. ISSN-L: 0017-3495 doi: http://dx.doi.org/10.3989/gya.0111141 
higher than that found in oils obtained from organic cultivation. There were significant differences in the secoiridoid content among Nocellara etnea oils obtained from olives cultivated at different altitudes. Nocellara etnea olives grown at $100 \mathrm{~m}$ produced oil with the highest content of secoiridoids, and the content decreased in oils obtained from olives grown at a higher altitude $(900 \mathrm{~m})$.

Phenolic acids were the first group of phenolic compounds to be identified in virgin olive oil (Servili et al., 2009). In recent years, phenolic acids have received considerable attention as they are essential to olive oil quality and nutritional properties. The phenolic acids observed in the VOOs in this study were $p$-coumaric and ferulic acids. Concentrations of ferulic acid ranged from 0.34 to $3.21 \mathrm{mg} \cdot \mathrm{kg}^{-1}$. In all the samples investigated, $p$-coumaric acid concentrations did not exceed $0.43 \mathrm{mg} \cdot \mathrm{kg}^{-1}$. Vanillic acid was not detected in Passulunara and Nocellara del belice organic olive oils. These results agree with those reported by other authors (Saitta et al., 2002). With regard to phenolic acid concentrations in the Novellara etnea variety at different altitudes, the highest $p$-coumaric acid concentration was found at $100 \mathrm{~m}\left(0.20 \mu \mathrm{g} \cdot \mathrm{kg}^{-1}\right)$, while cinnamic acid and ferulic acid concentrations were higher in oils from N. etnea grown at $900 \mathrm{~m}$.

Flavonoids and lignan groups of phenolic compounds abundant in plants are known to have many beneficial biological effects, including anti-inflammatory, antioxidant and oestrogenic activities (Adlercreutz, 2007). Considering flavone concentrations, luteolin and apigenin were more abundant in the Biancolilla and Nocellara etnea varieties. Luteolin concentrations ranged from 1.54 to $4.32 \mathrm{mg} \cdot \mathrm{kg}^{-1}$ and were higher than apigenin concentrations $\left(0.84-1.96 \mathrm{mg} \cdot \mathrm{kg}^{-1}\right)$. Nocellara etnea oils obtained from olive groves at an altitude of $0 \mathrm{~m}$ had higher flavonoid concentrations than those obtained from groves at a higher altitude. Concentrations of the lignan pinoresinol were within the range of $0.13-1.49 \mu \mathrm{g} \cdot \mathrm{kg}^{-1}$. Olive oils obtained from Nocellara etnea olive groves at an altitude of $900 \mathrm{~m}$ had higher pinoresinol concentrations than those obtained from groves at a lower altitude.

\subsection{Effect of olive oil phenolic compound extracts on MG-63 osteoblast cell proliferation}

Nutritional and pharmacological therapies are needed to aid in the prevention of bone loss due to aging. In this study, the potential effects of VOO phenolic extracts obtained from Sicilian monovarietal olive oils on the proliferation of human osteosarcoma cells were investigated. MG-63 osteoblast cells were cultured in the absence and presence of phenolic extract dilutions in a fresh culture medium. The highest solvent concentration in the culture media $(0.001 \%$, v/v methanol) had no significant effects on cell proliferation.
The hypothesis of this study was that the phenolic fractions of each VOO variety would have differing effects on the induction of osteoblast proliferation. MG-63 cells were treated with various concentrations of extracts to determine the biological activities of the complex multi-component phenolic extracts. All extracts, with the exception of Tonda iblea, stimulated MG-63 cell growth significantly in a non-concentration-dependent manner, with the following order of potency: Nocellara del belice $>$ Biancolilla $>$ Organic Nocellara del belice $>$ Nocellara etnea $0 \mathrm{~m}>$ Nocellara etnea $100 \mathrm{~m}>$ Nocellara etnea $900 \mathrm{~m}>$ Passulunara $>$ Tonda iblea. Treatment of osteoblast cells with olive oil phenolic extracts increased the number of cells by $13.77-30.98 \%$ compared with controls (Table 2 ).

Differences in the ability of individual phenolic extracts to stimulate osteoblast proliferation were observed (Table 2). For instance, concentrations of $0.001 \%$ and $0.0001 \%$ were needed to increase cell proliferation significantly when MG-63 cells were cultured in the presence of Passulunara and Nocellara etnea at $900 \mathrm{~m}$ phenolic extracts. On the contrary, the olive oil phenolic extracts of Biancolilla, Nocellara del Belice, Nocellara etnea at 0 and $100 \mathrm{~m}$ altitudes significantly increased the MG-63 cell proliferation at the lowest concentration.

The VOO phenolic extracts with the highest activity were those obtained from the Nocellara del belice variety, as they significantly increased cell proliferation by $30.98 \%$. In addition, treatment with organic Nocellara del belice VOO phenolic extracts increased cell proliferation by $28.46 \%$ at the lowest concentration. However, Tonda iblea phenolic extracts did not stimulate cell proliferation.

Although the impact of olive oil phenolic extracts on MG-63 cells is well-known, the mechanism by which they induce MG-63 cell proliferation is not fully understood. In this regard, certain observations may help describe this mechanism. Oxidative stress, which increases the level of intracellular reactive oxygen species, has been reported to inhibit bone metabolism (Hagiwara et al., 2011). Olive oil phenolic compounds have strong antioxidant properties (Visioli y Bernardini, 2011), and hydroxytyrosol has been shown to decrease $\mathrm{H}_{2} \mathrm{O}_{2}$ levels in MC3T3-E1 osteoblast cells (Hagiwara et al., 2011). In addition, it has been demonstrated that $\mathrm{H}_{2} \mathrm{O}_{2}$ suppresses differentiation markers (such as alkaline phosphatase activity), osteoblastic cell mineralization and type I collagen gene expression (Hosoya et al., 1998).

Even though the phenolic contents differed among the different VOOs studied, most phenolic extracts increased cell proliferation significantly. It should be noted that the effect on osteoblast proliferation was observed in a non-concentrationdependent manner. The oils obtained from the 
TABLE 2. Effect of Sicilian VOO phenolic extracts on MG-63 cell growth as determined by MTT. Cells were treated with various concentrations of VOO phenolic extracts or vehicle alone (control) for $24 \mathrm{~h}$

\begin{tabular}{|c|c|c|c|c|}
\hline Treatment & $\begin{array}{c}\text { Concentration } \\
(\% \mathrm{v} / \mathrm{v})\end{array}$ & $\begin{array}{l}\text { Proliferation } \\
{\text { (\% control })^{\mathrm{a}}}^{(\%)}\end{array}$ & $\mathbf{t}$ & $\mathbf{p}$ \\
\hline Control & & $100 \%$ & & \\
\hline \multirow[t]{3}{*}{ Biancolilla } & 0.001 & $127.76 \pm 11.66$ & -3.471 & 0.002 \\
\hline & 0.0001 & $128.72 \pm 4.96$ & -3.719 & 0.001 \\
\hline & 0.00001 & $127.59 \pm 8.45$ & -3.519 & 0.001 \\
\hline \multirow[t]{3}{*}{ Passulunara } & 0.001 & $124.49 \pm 5.04$ & -3.171 & 0.003 \\
\hline & 0.0001 & $121.24 \pm 6.87$ & -2.730 & 0.010 \\
\hline & 0.00001 & $115.34 \pm 11.92$ & -1.618 & 0.116 \\
\hline \multirow[t]{3}{*}{ Tonda iblea } & 0.001 & $110.96 \pm 19.53$ & -1.073 & 0.295 \\
\hline & 0.0001 & $102.17 \pm 6.21$ & -0.731 & 0.473 \\
\hline & 0.00001 & $101.57 \pm 6.42$ & -0.523 & 0.607 \\
\hline \multirow{3}{*}{$\begin{array}{l}\text { Nocellara del } \\
\text { belice }\end{array}$} & 0.001 & $130.98 \pm 2.00$ & -4.039 & 0.0001 \\
\hline & 0.0001 & $123.65 \pm 8.81$ & -3.010 & 0.005 \\
\hline & 0.00001 & $119.00 \pm 11.05$ & -2.385 & 0.024 \\
\hline \multirow{3}{*}{$\begin{array}{l}\text { Organic } \\
\text { Nocellara del } \\
\text { belice }\end{array}$} & 0.001 & $127.73 \pm 3.78$ & -3.603 & 0.001 \\
\hline & 0.0001 & $124.02 \pm 2.78$ & -3.127 & 0.004 \\
\hline & 0.00001 & $128.46 \pm 2.08$ & -3.710 & 0.001 \\
\hline \multirow{3}{*}{$\begin{array}{l}\text { Nocellara } \\
\text { etnea } 0 \mathrm{~m}\end{array}$} & 0.001 & $126.01 \pm 7.47$ & -8.513 & 0.0001 \\
\hline & 0.0001 & $125.49 \pm 6.81$ & -8.716 & 0.0001 \\
\hline & 0.00001 & $113.77 \pm 13.99$ & -3.004 & 0.007 \\
\hline \multirow{3}{*}{$\begin{array}{l}\text { Nocellara } \\
\text { etnea } 100 \mathrm{~m}\end{array}$} & 0.001 & $125.02 \pm 6.31$ & -8.842 & 0.0001 \\
\hline & 0.0001 & $121.054 \pm 6.70$ & -6.873 & 0.0001 \\
\hline & 0.00001 & $116.40 \pm 12.46$ & -4.446 & 0.0001 \\
\hline \multirow{3}{*}{$\begin{array}{l}\text { Nocellara } \\
\text { etnea } 900 \mathrm{~m}\end{array}$} & 0.001 & $125.27 \pm 15.97$ & -4.960 & 0.0001 \\
\hline & 0.0001 & $118.39 \pm 16.25$ & -3.559 & 0.002 \\
\hline & 0.00001 & $106.43 \pm 10.29$ & -1.030 & 0.314 \\
\hline
\end{tabular}

a The values are the mean \pm SD (\%) from three separate experiments performed in triplicate. Statistically significant differences were analyzed by Student's t-test.

Tonda iblea variety did not have any effect on osteoblast cell proliferation, and it has been noted that this variety has a low total phenol content. However, there are no major qualitative differences in the concentration of phenolic compounds between the Tonda iblea variety and other varieties studied. Passulunara and Nocellara etnea varieties grown at $900 \mathrm{~m}$ induce a significant increase in cell proliferation at a phenol extract concentration of $0.001 \%$, even though they are varieties with low total phenolic contents. In addition, phenol extracts from oils obtained from the Nocellara etnea variety grown at $100 \mathrm{~m}$, which is the variety with the highest total phenol content,did not exert the greatest effect on osteoblast cell proliferation. These data suggest that other substances present in this extract may be responsible for or influence the effect on MG-63 cell proliferation. Further studies are required to identify other bioactive substances and the mechanisms by which VOO phenolic extracts induce MG-63 cell proliferation.

The mean dietary intake of virgin olive oil phenols has been estimated to be approximately $68.5 \pm 104.0 \mathrm{mg} \cdot \mathrm{day}^{-1}$ in a Mediterranean population, which represented approximately $11 \%$ of the total phenolic compound intake (Treserra-Rimbau et al., 2013). Considering these amounts, the concentration of phenols used in this study are easily achieved with the actual daily intake of virgin olive oil and are potentially reached in the intestine after the consumption of olive oil. However, we should acknowledge that in vitro studies on biocompounds should always consider intestinal absorption and biotransformation. In this regard, research on humans (Miró-Casas et al., 2002; Visioli et al., 2003) and animals (Tuck et al., 2002) has shown that the dominant virgin olive oil phenols, hydroxytyrosol and tyrosol, are bioavailable and, as such, a fraction of the oral dose can be recovered in the urine, with $>90 \%$ of the urinary excretion in the form of metabolites, which are mainly $\mathrm{O}$-glucoronoided conjugates. In addition, after virgin olive oil administration, O-methylated forms, such as homovanillyl alcohol or homovanillyl acid, and monosulphated conjugates have been identified in plasma and urine (Mateos et al., 2011; Miró-Casas et al., 2002; Visioli et al., 2003). A further study found that the absorption of administered ligstroside-aglycone, hydroxytyrosol, tyrosol and oleuropein aglycone was as high as $55-66 \%$ of the ingested phenols in humans, indicating an effective intestinal absorption of these compounds (Vissers et al., 2002). Unfortunately, the knowledge available on the metabolic fate of VOO-derived complex phenols is still scarce (Lozano-Sánchez et al., 2010), hence the need for research on the plasma and urine concentrations of the free forms of various secoiridoid aglycones.

Although these experimental studies support the hypothesis that VOO phenolic compounds exert a beneficial effect on osteoblasts further studies assessing the in vivo accessibility of VOO phenolic compounds to osteoblast cells should be carried out. Accordingly, as the metabolism of VOO phenolic compounds is not well understood, it is necessary to perform further in vitro studies on the intestinal absorption and biotransformation of such compounds.

\subsection{Statistical Analysis}

As shown in Table 3, an ANOVA demonstrated that MG-63 cell proliferation is influenced by the variety and concentration of olive oil ( $p=0.0001$ and $p=0.001$, respectively). The adjusted $\mathrm{R}$-squared value was 0.802 , indicating 
TABLE 3. Results of an analysis of variance for MG-63 cell growth as a function of the olive oil variety and concentration and for phenol concentrations as a function of the olive oil variety

\begin{tabular}{|c|c|c|c|c|c|c|}
\hline Source & Sum of squares & Degrees of freedom & Mean square & F Statistic & $P$ value & Adjusted R squared \\
\hline \multicolumn{7}{|c|}{ MG-63 proliferation $^{1}$} \\
\hline Corrected Model & 1417.5 & 9 & 157.5 & 11.3 & 0.0001 & 0.802 \\
\hline Intercept & 348367.9 & 1 & 348367.9 & 25046.9 & 0.0001 & \\
\hline Concentration & 303.4 & 2 & 151.7 & 10.9 & 0.001 & \\
\hline Olive oil variety & 1114.1 & 7 & 159.1 & 11.4 & 0.0001 & \\
\hline Error & 194.7 & 14 & 13.9 & & & \\
\hline Total & 349980.1 & 24 & & & & \\
\hline Corrected Total & 1612.2 & 23 & & & & \\
\hline \multicolumn{7}{|l|}{ Phenol alcohols ${ }^{2}$} \\
\hline Inter-group & 128.256 & 7 & 18.322 & 9.842 & 0.0001 & 0.811 \\
\hline Intra-group & 29.785 & 16 & 1.862 & & & \\
\hline Total & 158.041 & 23 & & & & \\
\hline \multicolumn{7}{|l|}{ Secoiridoids $^{2}$} \\
\hline Inter-group & 99072.4 & 7 & 14153.2 & 119.142 & 0.0001 & 0.981 \\
\hline Intra-group & 1900.6 & 16 & 118.792 & & & \\
\hline Total & 100973.0 & 23 & & & & \\
\hline \multicolumn{7}{|l|}{ Phenolic acids ${ }^{2}$} \\
\hline Inter-group & 21.211 & 7 & 3.030 & 728.43 & 0.0001 & 0.996 \\
\hline Intra-group & 0.067 & 16 & 0.004 & & & \\
\hline Total & 21.278 & 23 & & & & \\
\hline \multicolumn{7}{|l|}{ Flavonoids $^{2}$} \\
\hline Inter-group & 31.385 & 7 & 4.484 & 32.282 & 0.0001 & 0.933 \\
\hline Intra-group & 2.222 & 16 & 0.139 & & & \\
\hline Total & 33.607 & 23 & & & & \\
\hline \multicolumn{7}{|l|}{ Lignans $^{2}$} \\
\hline Inter-group & 3.237 & 7 & 0.462 & 553.930 & 0.0001 & 0.995 \\
\hline Intra-group & 0.013 & 16 & 0.001 & & & \\
\hline Total & 3.251 & 23 & & & & \\
\hline \multicolumn{7}{|c|}{ Total phenolic compounds ${ }^{2}$} \\
\hline Inter-groups & 492390.1 & 7 & 70341.4 & 1106.1 & 0.0001 & 0.997 \\
\hline Intra-groups & 1017.4 & 16 & 63.5 & & & \\
\hline Total & 493407.6 & 23 & & & & \\
\hline
\end{tabular}

\footnotetext{
${ }^{1}$ Two-way ANOVA: ${ }^{2}$ One-way ANOVA.
}

that olive oil variety and phenol concentrations explain $80.2 \%$ of variability in the proliferation. The Bonferroni test showed that the Tonda iblea variety had different effects on MG-63 proliferation compared to the rest of the olive oil varieties studied. In addition, it was demonstrated that there are statistically significant differences $(p=0.001)$ between the effects of the $0.001 \%$ and $0.00001 \%$ sample concentrations on MG-63 proliferation. On the contrary, there are no significant differences in the effect of the $0.001 \%$ concentrations on cell proliferation with respect to the other concentrations studied $(p>0.005)$. An ANOVA of the phenol concentration revealed the influence of the variety of olive oil in all the groups of compounds studied $(p=0.0001)$. The statistical test allowed us to group the eight varieties of olive oil into five categories according to their phenol content: I (Tonda iblea and Nocellara etnea $900 \mathrm{~m}$ ), II (Biancolilla, Passulunara and Organic Nocellara del belice), III (Nocellara del belice), IV (Nocellara Etnea $0 \mathrm{~m}$ ) and V (Nocellara Etnea $100 \mathrm{~m}$ ).

Multivariate PCA was used to further describe the differences observed in the VOO samples obtained from different cultivars and grove locations. The score and loading plot obtained by PCA 

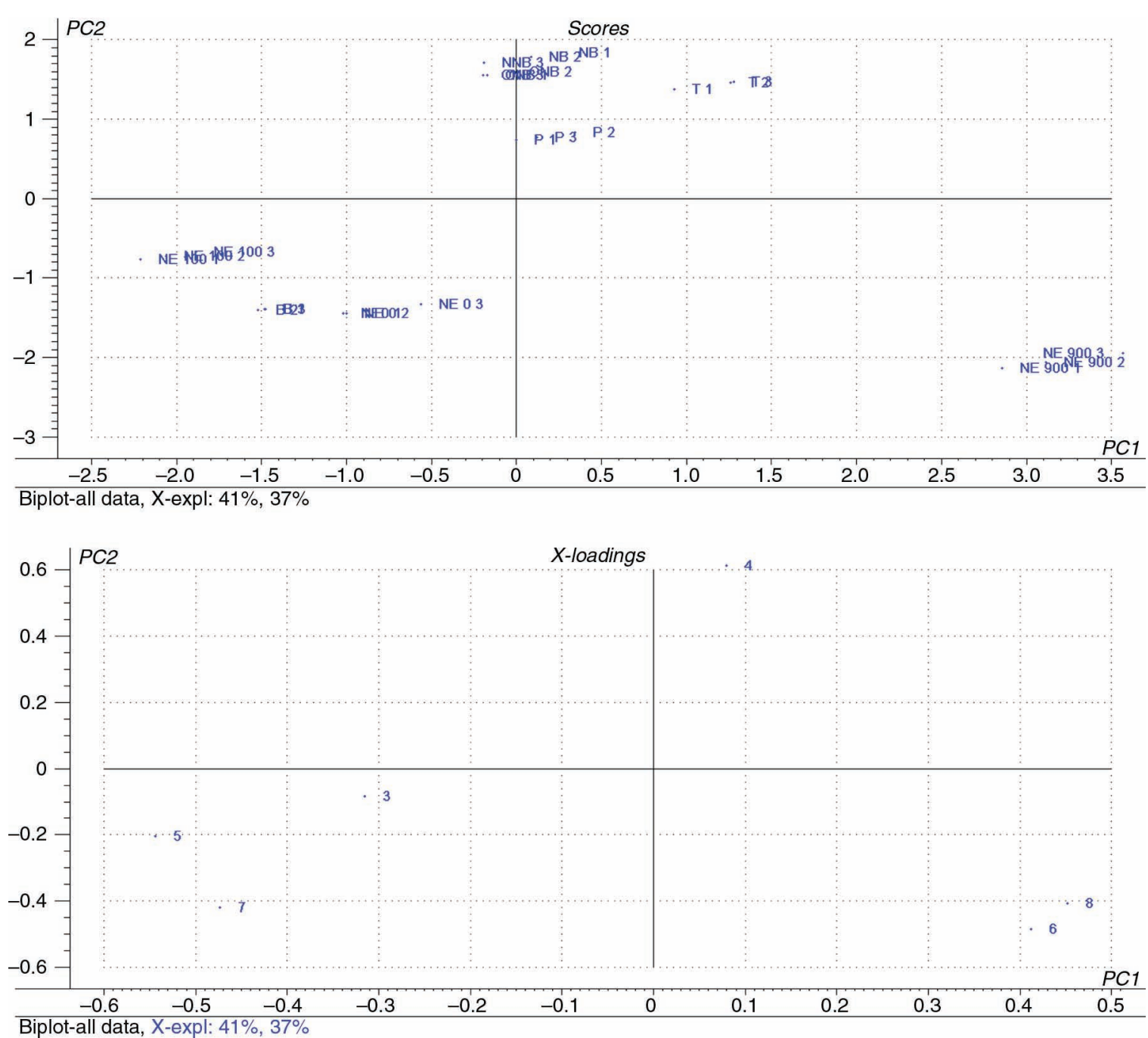

FIgURE 1. Bi-Plot (A. Scores and B. Loadings) of the principal component analysis model for the Sicilian VOO. Samples are plotted by selected letters, Biancolilla (B), Passulunara (P), Tonda iblea (T), Nocellara del belice (NB), Organic Nocellara del belice (ONB), and Nocellara etnea (NE), and by numbers, 1, 2 and 3, corresponding to the $0.001,0.0001$ and $0.0001 \%$ extract concentration in osteoblast cell culture medium.

based on the phenol concentration values and the effect of the VOOs on cell proliferation are shown in Figure 1. Across the first-dimension PC1 (accounting for $41 \%$ of the total variance), the type of cultivar and the grove location were discriminated, whereas across the second dimension (accounting for $37 \%$ of the total variance), the cultivation method (organic or conventional for Nocellara del belice) and phenolic extract concentrations in osteoblast cells were discriminated. Table 4 shows the loading of the variables for the Principal Components 1 and 2. Secoiridoids and flavonoids showed the highest loading in Component 1 and phenolic acids and alcohols in Component 2.

Comparisons between the two PCA plots (score and loading) indicated that the variables flavonoids, phenolic acids and lignans were mainly responsible for the discrimination of the Nocellara etnea olive oils obtained at $900 \mathrm{~m}$. This cultivar, along with Tonda iblea, obtained the highest scores on Component 1, and Nocellara del Belice (organic and conventional) obtained the highest scores on Component 2.

To characterize olive oils from the Nocellara etnea varieties at different altitudes, a multivariate analysis was applied to the chemical data and to the effect of this olive oil variety on osteoblast cell proliferation. PCA discriminated the samples by altitude (Figure 2; Table 5), thus highlighting the important role of the environment in determining the phenolic profile and nutritional properties of virgin olive oil (Servili et al., 2009). Comparisons 
TABLE 4. X Loading of the variables included in Principal Components 1 and 2 of Sicilian VOO

\begin{tabular}{llrr}
\hline & \multicolumn{1}{c}{ Variable } & PC1 & PC2 \\
\hline $\mathbf{1}$ & MG-63 Proliferation & -0.32 & -0.08 \\
$\mathbf{2}$ & Phenol alcohols & 0.08 & 0.61 \\
$\mathbf{3}$ & Secoiridoids & -0.54 & -0.20 \\
$\mathbf{4}$ & Phenolic acids & 0.41 & -0.48 \\
$\mathbf{5}$ & Flavonoids & -0.47 & -0.42 \\
$\mathbf{6}$ & Lignans & 0.45 & -0.41 \\
\hline
\end{tabular}

between the two PCA plots (score and loading) indicated that the variables lignans and phenolic acids were mainly responsible for the discrimination of the oils at $900 \mathrm{~m}$ of altitude, whereas the variables secoiridoids were observed at $100 \mathrm{~m}$ of altitude for the oils. Finally, osteoblast cell proliferation and flavonoids were major contributors to the separation of Nocellara etnea oils at the lowest altitude.

\section{CONCLUSION}

In this study, the olive oil phenolic content and its effect on human osteosarcoma cell proliferation showed consistent variability according to the type of cultivar and the grove altitude, even within the same type of cultivar. This behavior demonstrated that the cultivar and the grove location can significantly affect the chemical and health-promoting characteristics of virgin olive oil. Although these

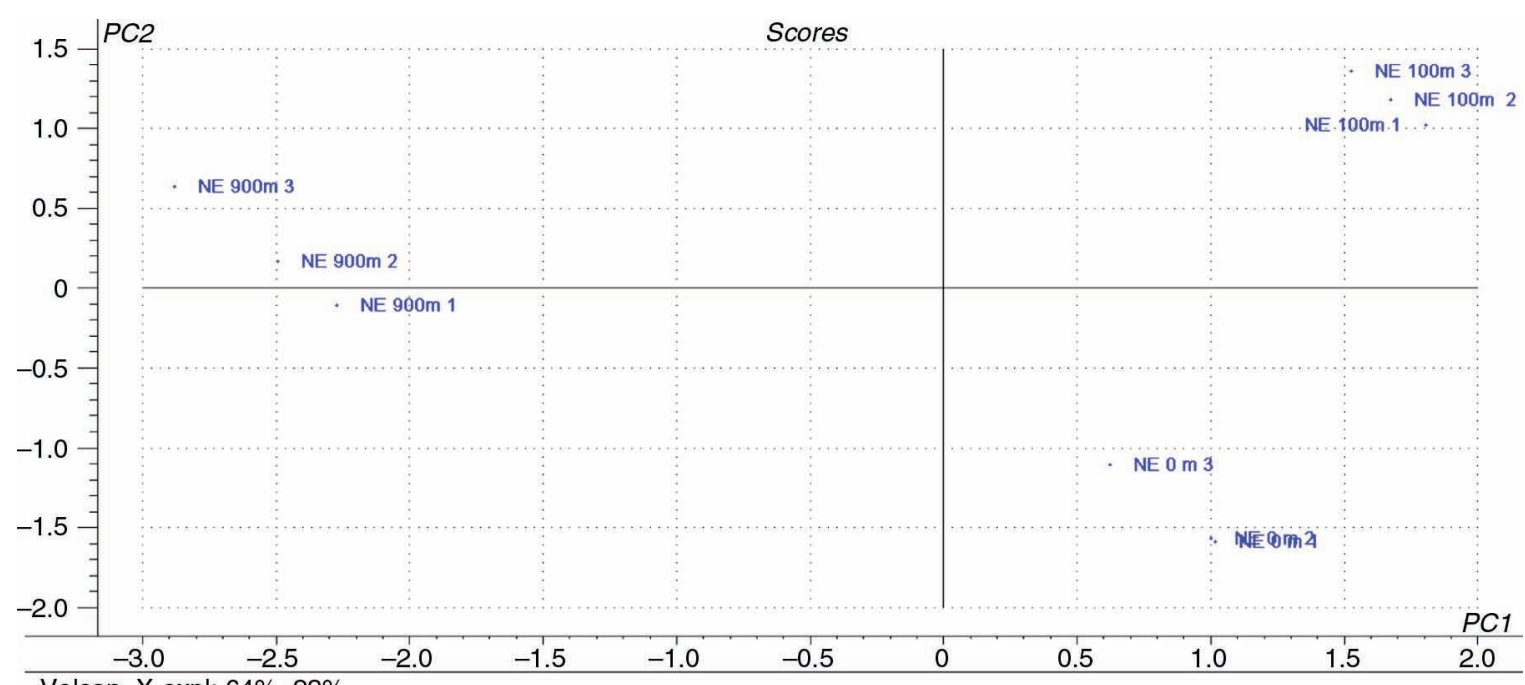

Volcan, X-expl: $64 \%, 23 \%$

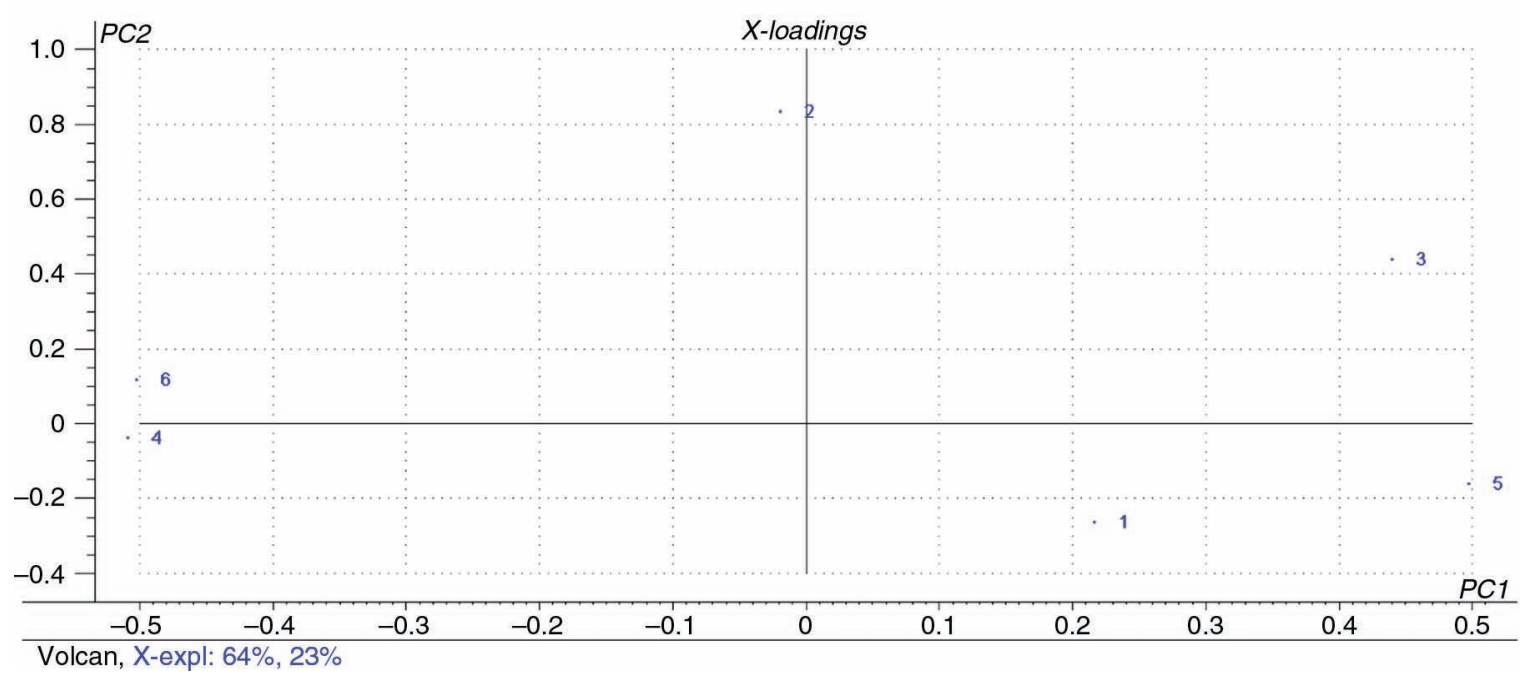

FIGURE 2. Bi-Plot (A. Scores and B. Loadings) of the principal component analysis model for Nocellara etnea (NE) VOO at three different altitudes. Samples are plotted by numbers, 1, 2 and 3, corresponding to the $0.001,0.0001$ and $0.0001 \%$ extract concentration in osteoblast culture medium. 
TABLE 5. X Loading of the variables included in Principal Components 1 and 2 of Nocellara etnea VOO

\begin{tabular}{llcc}
\hline & \multicolumn{1}{c}{ Variable } & PC1 & PC2 \\
\hline $\mathbf{1}$ & MG-63 Proliferation & 0.21 & -0.26 \\
$\mathbf{2}$ & Phenol alcohols & -0.001 & 0.83 \\
$\mathbf{3}$ & Secoiridoids & 0.44 & 0.43 \\
$\mathbf{4}$ & Phenolic acids & -0.50 & -0.003 \\
$\mathbf{5}$ & Flavonoids & 0.498 & -0.16 \\
$\mathbf{6}$ & Lignans & -0.50 & 0.11
\end{tabular}

experimental studies support the hypothesis that VOO phenolic fractions exert a beneficial effect on bone health, further studies assessing the in vivo accessibility of VOO phenolic compounds to osteoblast cells should be performed.

\section{ACKNOWLEDGMENTS}

We wish to thank Beatriz Cañabate and the Granada's Laboratory of Food Analysis staff for their assistance in laboratory techniques.

\section{REFERENCES}

Adlercreutz H. Lignans and human health. 2007. Crit. Rev. Clin. Lab. Sci. 44, 483-525. http://dx.doi.org/10.1080/ 10408360701612942 .

Baccouri B, Ben Termine S, Campeol E, Cioni PL, Daoud, D, Zarrouk M. 2007. Application of solid-phase microextraction to the analysis of volatile compunds in virgin olive oils from five new cultivars. Food Chem. 102, 850-856. http:// dx.doi.org/10.1016/j.foodchem.2006.06.012.

Bendini A, Cerretani L, Carrasco-Pancorbo A, GómezCaravaca AM, Segura-Carretero A, Fernández-Gutiérrez A, Lercker G. 2007. Phenolic molecules in virgin olive oils: a survey of their sensory properties, health effects, antioxidant activity and analytical methods. An overview of the last decade. Molecules 12, 1679-1719. http://dx.doi.org/ $10.3390 / 12081679$.

Corona G, Tzounis X, Assunta Dessì M, Deiana M, Debnam ES, Visioli F, Spencer JP. 2006. The fate of olive oil polyphenols in the gastrointestinal tract: implications of gastric and colonic microflora-dependent biotransformation. Free Radic. Res. 40, 647-658. http://dx.doi. org/10.1080/10715760500373000.

Dugo C, Alfa M, La Pera L, Mavrogeni E, Policino D, Moisano R, Pizziment G. 2004. Characterization of Sicillian Virgin Olive Oils. Note X. A comparison between Cerasuda and Nocellara del Belica varieties, Grasas Aceites 55, 415-422. http://dx.doi.org/10.3989/gya.2004.v55.i4.209.

Fernández-Real JM, Bulló M, Moreno-Navarrete JM, Ricart W, Ros E, Estruch R, Salas-Salvadó J. 2012. A Mediterranean diet enriched with olive oil is associated with higher serum total osteocalcin levels in elderly men at high cardiovascular risk. J. Clin. Endocrinol. Metab. 97, 3792-3798. http:// dx.doi.org/10.1210/jc.2012-2221.

Hagiwara K, Goto T, Araki M, Miyazak, H, Hagiwara H. 2011. Olive polyphenol hydroxytyrosol prevents bone loss. Eur. J. Pharmacol. 662, 78-84. http://dx.doi.org/10.1016/j. ejphar.2011.04.023.

Hosoya S, Suzuki H, Yamamoto M, Kobayashi K, Abiko Y. 1998. Alkaline phosphatase and type I collagen gene expressions were reduced by hydroxyl radical-treated fibronectin substratum. Mol. Genet. Metab. 65, 31-34. http:// dx.doi.org/10.1006/mgme.1998.2734.
International Olive Oil Council (IOOC), Document COI/T.20/ DOC. 29. 2009. International Olive Oil Council, Madrid.

Jiménez B, Sánchez-Ortiz A, Lorenzo ML, Rivas A. 2013. Influence of fruit ripening on agronomic parameters, quality indices, sensory attributes and phenolic compounds of Picudo olive oils. Food Res. Int. 54, 1860-1867. http:// dx.doi.org/10.1016/j.foodres.2013.08.016.

Kim TH, Jung JW, Ha BG, Hong JM, Park EK, Kim HJ, Kim SY. 2011. The effects of luteolin on osteoclast differentiation, function in vitro and ovariectomy-induced bone loss. J. Nutr. Biochem. 22, 8-15. http://dx.doi.org/10.1016/j. jnutbio.2009.11.002.

Lee JW, Ahn JY, Hasegawa S, Cha BY, Yonezawa T, Nagai K, Seo HJ, Jeon WB, Woo JT. 2009. Inhibitory effect of luteolin on osteoclast differentiation and function. Cytotechnology 61, 125-34. http://dx.doi.org/10.1007/s10616-010-9253-5.

Lozano-Sánchez J, Segura-Carretero A, Menendez JA, OliverasFerraros C, Cerretani L, Fernández-Gutiérrez A. 2010. Prediction of extra virgin olive oil varieties through their phenolic profile. Potential cytotoxic activity against human breast cancer cells. J. Agric. Food Chem. 22, 9942-55. http://dx.doi.org/10.1021/jf101502q

Martínez JM, Muñoz E, Alba J, Lanzon A. 1975. Informe sobre la utilización del analizador de rendimientos "Abencor". Grasas y Aceites 26, 379-385.

Mateos R, Espartero JL, Trujillo M, Ríos JJ, León-Camacho M, Alcudia F, Cert A. 2001. Determination of phenols, flavones, and lignans in virgin olive oils by solid-phase extraction and high-performance liquid chromatography with diode array ultraviolet detection. J. Agric. Food Chem. 49, 2185-2192. http://dx.doi.org/10.1021/jf0013205.

Mateos R, Pereira-Varo G, Saha S, Cert R, Redondo-Horcajo M, Bravo L, Kroon PA. Acetylation of hydroxytyrosol enhances its transport across differentiated Caco-2 cell monolayers. Food Chem. 125, (2011) 865-872.

Miró-Casas E, Covas MI, Farre M, Fito M, Ortuño J, Weinbrenner T, Roset P, de la Torre R. 2003. Hydroxytyrosol disposition in humans. Clin Chem. 49, 945-52. http:// dx.doi.org/10.1373/49.6.945.

Mousa YM, Gerasopoulos D. 1996. Effect of Altitude on Fruit and Oil Quality Characteristics of 'Mastoides' Olives. J. Sci. Food Agr. 71, 345-350. http://dx.doi. org/10.1002/(SICI)1097-0010(199607)71:3<345::AIDJSFA 590>3.0.CO;2-T

Napolitano A, Morales F, Sacchi R, Fogliano V. 2008. Relationship between virgin olive oil phenolic compounds and acrylamide formation in fried crisps. J. Agric. Food Chem. 56, 2034-2040. http://dx.doi.org/10.1021/jf0730082.

Ouni Y, Taamalli A, Guerfel M, Abdelly Ch, Zarrouk M, Flamini G. 2012. The phenolic compounds and compositional quality of Chétoui virgin olive oil: Effect of altitude. Afr. J. Biotechnol. 11, 11842-11850.

Patumi M, Terenziani S, Ridolfi M, Fontanazza G. 2003. Effect of fruit stoning on olive oil quality, J. Am. Oil Chem. Soc. 80, 249-255. http://dx.doi.org/10.1007/s11746-003-0685-1.

Poiana M, Romeo FV. 2006. Changes in chemical and microbiological parameters of some varieties of Sicily olives during natural fermentation. Grasas Aceites, 57, 402-408. http:// dx.doi.org/10.3989/gya.2006.v57.i4.66.

Puel C, Mardon J, Agalias A, Davicco MJ, Lebecque P, Mazur A, et al. 2008. Major phenolic compounds in olive oil modulate bone loss in an ovariectomy/inflammation experimental model. J. Agric. Food Chem. 56, 9417-9422. http:// dx.doi.org/10.1021/jf801794q.

Puel C, Mardon J, Kati-Coulibaly S, Davicco MJ, Lebecque P, Obled C, et al. 2007. Black Lucques olives prevented bone loss caused by ovariectomy and talc granulomatosis in rats. Br. J. Nutr. 97, 1012-1020. http://dx.doi.org/10.1017/ S0007114507659030.

Rivas A, Romero A, Mariscal-Arcas M, Monteagudo C, Feriche B, Lorenzo ML, Olea F. 2013. Mediterranean diet and bone mineral density in two age groups of women. Int. J. Food Sci. Nutr. 64, 155-161. http://dx.doi.org/10.3109/096 37486.2012.718743.

Rivas A, Sánchez-Ortiz A, García-Moyano J, Lorenzo ML. 2013. Phenolic acid content and sensory properties of two 
Spanish monovarietal virgin olive oils. Eur. J. Lipid Sci. 115, 621-630. http://dx.doi.org/10.1002/ejlt.201200371.

Saitta M, Lo Curto S, Salvo F, Di Bella G, Dugo G. 2002. Gas chromatographic-tandem mass spectrometric identification of phenolic compounds in Sicilian olive oils, Anal. Chim. Acta 466, 335-344. http://dx.doi.org/10.1016/ S0003-2670(02)00572-X.

Santiago-Mora R, Casado-Díaz A, De Castro MD, QuesadaGómez JM. 2011. Oleuropein enhances osteoblastogenesis and inhibits adipogenesis: the effect on differentiation in stem cells derived from bone marrow. Osteoporos Int. 22, 675-684. http://dx.doi.org/10.1007/ s00198-010-1270-x.

Servili M, Esposto S, Fabiani R, Urbani S, Taticchi A, Mariucci F, Selvaggini R, Montedoro GF. 2009. "Phenolic compounds in olive oil: Antioxidant, health and organoleptic activities according to their chemical structure", Inflammopharmacology, 17, 76-84. http://dx.doi.org/10. 1007/s10787-008-8014-y.

Suárez M, Valls RM, Romero MP, Macià A, Fernández S, Giralt M, Solà R, Motilva MJ. 2011. Bioavailability of phenols from a phenol-enriched olive oil. Br J Nutr. 106, 1691-701. http://dx.doi.org/10.1017/S0007114511002200.
Tresserra-Rimbau A, Medina-Remón A, Pérez-Jiménez J, Martínez-González MA Covas MI, Corella D, SalasSalvadó J, Gómez-Gracia E, Lapetra J, Arós F, Fiol M, Ros E, Serra-Majem L, Pintó X, Muñoz MA, Saez GT, RuizGutiérrez V, Warnberg J, Estruch R, Lamuela-Raventós RM. 2013. Dietary intake and major food sources of polyphenols in a Spanish population at high cardiovascular risk: the PREDIMED study. Nutr. Metab. Cardiovasc Dis. 23, 953-9. http://dx.doi.org/10.1016/j. numecd.2012.10.008.

Vissers MN, Zock PL, Roodenburg AJ, Leenen R, Katan MB. Olive oil phenols are absorbed in humans. 2002. J. Nutr. 132, 409-17.

Visioli F, Bernardini E. 2011. Extra virgin olive oil's polyphenols: biological activities. Curr. Pharm. Des. 17, 786-804. http://dx.doi.org/10.2174/138161211795428885.

Visioli F, Galli C, Grande S, Colonnelli K, Patelli C, Galli G, Caruso D. 2003. Hydroxytyrosol excretion differs between rats and humans and depends on the vehicle of administration. J Nutr. 133, 2612-5.

Visioli F, Galli C, Bornet F, Mattei A, Patelli R, Galli G, Caruso D. 2000. Olive oil phenolics are dose-dependently absorbed in humans. FEBS Lett. 468, 159-60. http://dx.doi.org/ 10.1016/S0014-5793(00)01216-3. 